\title{
EDGAR ALLAN POE E O SURGIMENTO DO CONTO ENQUANTO GÊNERO DE FICÇÃO
}

\author{
Greicy Pinto Bellin \\ Universidade Federal do Paraná
}

\begin{abstract}
Resumo: o objetivo do presente trabalho é descrever, discutir e analisar o surgimento do conto enquanto gênero de ficção, tendo como ponto de partida uma reflexão a respeito de Review of Twice-Told Tales, resenhas críticas de Edgar Allan Poe sobre os contos de um de seus contemporâneos, o escritor Nathaniel Hawthorne. Em tais textos, Poe apresenta a teoria da unidade de efeito, juntamente com a tese de que o conto poderia ser o veículo apropriado para a expressão máxima dos talentos de um artista. Além disso, será analisado o contexto literário norte-americano de princípios do século XIX, período no qual Poe produziu sua obra e que assistiu à consolidação do conto enquanto gênero ficcional. Neste sentido, serão abordados alguns aspectos do referencial teórico existente sobre narrativas curtas, a fim de problematizar alguns aspectos suscitados pela análise de Poe. Por último, serão feitas algumas considerações a respeito das ressonâncias de Poe na crítica literária, considerando que Mário de Andrade, Machado de Assis e Julio Cortázar retomam, rediscutem e reelaboram algumas noções propostas por Poe a respeito do conto.
\end{abstract}

Palavras-chave: Conto. Gênero de ficção. Unidade de efeito

\section{Introdução}

Edgar Allan Poe foi poeta, ficcionista, crítico literário e editor. Sua figura até hoje é alvo de inúmeros debates no campo dos estudos literários, seja pelo seu consciente e preciso trabalho com a linguagem, ou por ter ajudado a difundir o estereótipo do poeta maldito, que influenciou vários poetas de gerações posteriores ao Romantismo.

Como escritor, Poe é um dos precursores da literatura de ficção científica e fantástica modernas. Seus contos de terror, tais como "A queda da casa de Usher", "O gato preto" e "O coração denunciador", só para citar alguns, mergulham fundo na psique humana e provocam estados de tensão violenta, características que fizeram com que o autor fosse elevado à categoria de mestre do horror. Outros de seus contos, tais como "Os crimes da Rua Morgue", 
"A carta roubada" e "O mistério de Marie Roget", figuram entre as primeiras obras reconhecidas como policiais, exercendo grande influência, no século XIX, sobre a obra de Arthur Conan Doyle, e no século XX, sobre os romances de Agatha Christie. Além das narrativas detetivescas e de mistério, Poe escreveu sátiras, contos de humor e de ficção científica, tais como "The Balloon Hoax", no qual narra o aparecimento de novas tecnologias como os balões de ar quente. Ao mesmo tempo em que ajudou a lapidar uma tradição literária independente dos padrões ingleses, Poe mantinha-se preso a certos padrões literários europeus, em especial à vertente gótica do Romantismo inglês e à obra da escritora Ann Radcliffe.

Como poeta, Poe sofre uma série de influências: Lord Byron, William Wordsworth e Samuel Taylor Coleridge, seja na caracterização de personagens noturnos e boêmios, seja nas descrições poéticas da natureza, ou na preocupação em retratar o mistério e o sobrenatural. O autor também inovou a forma de se escrever poesia ao produzir os ensaios "O princípio poético" e "A racionalidade do verso", nos quais preconizava a preponderância dos aspectos formais sobre os de conteúdo. Outro ensaio de grande importância é "A filosofia da composição", no qual ele relata como compôs o poema "O corvo", mostrando que o fazer poético poderia ser uma elaboração racional e desmistificando a noção de que a poesia era uma simples expressão dos sentimentos do artista.

Como editor, Poe atuou em revistas de Richmond, Filadélfia e Nova Iorque. O autor foi auxiliado por John Pendleton Kennedy, o principal mecenas literário do sul dos EUA. Com a ajuda de Kennedy, ele se tornou a figura literária de maior importância nesta região, opondo-se de maneira ferrenha ao transcendentalismo ${ }^{1}$ predominante na literatura da Nova Inglaterra. Isto lhe garantiu a antipatia de escritores como o transcendentalista Ralph Waldo Emerson, fazendo com que ele se tornasse "uma figura controversa no mercado editorial norte-americano",2 (HAYES, 2002, p. 6).

\footnotetext{
${ }^{1}$ Primeiro movimento literário norte-americano, liderado por Ralph Waldo Emerson e Henry David Thoreau, surgido entre 1815 e 1836 na pequena cidade de Concord, no Estado de Massuchussets, que se configurou como uma forte reação contra o racionalismo do século XVIII e conferiu profundidade filosófica à literatura norteamericana. Os transcendentalistas afirmavam que o indivíduo poderia transcender a realidade e dar origem a uma nova forma de pensamento. Para eles, o homem é o centro espiritual do universo, e pode encontrar sozinho o caminho para a natureza e para o cosmos. Dentro desta perspectiva as convenções literárias e sociais não eram úteis e sim perigosas, pois o escritor deveria encontrar uma forma, uma voz e um conteúdo literário autênticos. A filosofia transcendentalista é um misto de neoplatonismo, filosofia idealista alemã e misticismo oriental, tendo influenciado bastante a literatura norte americana posterior, desde Walt Whitman até o movimento beat na década de 1960.

2 "A controversial figure in the American literary market". ( tradução nossa)
} 
Com base nestas ideias, o objetivo deste trabalho é descrever, discutir e analisar o surgimento do conto enquanto gênero de ficção, tendo como ponto de partida as reflexões de Poe em Review of Twice Told-Tales, um conjunto de resenhas críticas publicadas na revista literária Graham's Magazine nos anos de 1842 e 1847. Em tais textos, Poe analisa uma coletânea de contos de um de seus contemporâneos, o escritor Nathaniel Hawthorne, da Nova Inglaterra, argumentando que a ficção curta seria o veículo mais apropriado para a expressão máxima dos talentos de um artista. Além disso, o autor propõe a teoria da unidade de efeito, que preconiza que uma narrativa deve ser lida de uma só assentada, do contrário "os interesses do mundo que intervêm durante as pausas da leitura modificam, desviam, anulam, em maior ou menos grau, as impressões do livro" (POE, 2004, p. 3). Ao defender esta tese, Poe se posiciona contra grande parte do fazer literário de sua época. De acordo com Robert Spiller, as opiniões sobre Poe na época romântica eram divergentes, mas preponderantemente negativas: "Tennyson o achava um gênio, e Emerson acreditava que ele era um homem da selva. Henry James pensava que o fascínio em relação à obra de Poe refletia um estado primitivo de consciência". Paul Valéry, por sua vez, acreditava que Poe havia contribuído muito para a crítica literária com suas ideias vanguardistas (SPILLER, 1963, p. 321). Outros críticos acreditam que Poe era uma alma perturbada, fato que ajuda a explicar sua falta de sucesso profissional (TOMC, apud HAYES, 2002, p. 21). E o escritor Robert Louis Stevenson, em um ensaio intitulado "A academia", expressou sua convicção a respeito do talento de Poe mas criticou sua imagem pessoal, pois também acreditava que o estereótipo do alcoólatra que intercalava períodos criativos com crises depressivas foi um empecilho para o estabelecimento de uma reputação respeitável (STEVENSON, apud SPILLER, 1963, p. 322).

A crítica das últimas décadas tenta desmistificar a imagem de Poe como alienado e passa a se concentrar na maestria de seu trabalho com a linguagem literária. $\mathrm{Na}$ visão de Ricardo ARAÚJO (2002, p. 37), o poeta se movia entre o grotesco, o arabesco ${ }^{3}$ e o bizarro, características estas que eram personificadas nas maldades dos protagonistas masculinos. E para William Carlos Williams, foi o primeiro escritor a fazer da literatura norte-americana

\footnotetext{
${ }^{3}$ De acordo com os dicionários de língua portuguesa, "arabesco" apresenta duas definições. A primeira se refere a uma elaborada combinação de formas geométricas semelhantes às de animais e plantas. São elementos da arte islâmica, normalmente usados para enfeitar as paredes das mesquitas. A segunda definição se refere ao ato de rabiscar de forma pouco legível. Tales of the grotesque and arabesque é o título original das Histórias Extraordinárias de Poe, nas quais o "grotesco" corresponderia às narrativas satíricas, e o "arabesco" às narrativas de terror, que causam calafrios no leitor. A primeira definição de "arabesco" foi usada por Poe no ensaio "Filosofia do mobiliário", no qual discorre sobre arquitetura. Baseando-se em todas estas informações, chegamos à conclusão de que "arabesco", em seu sentido figurado, significa algo exótico e misterioso, já que a palavra é também usada no conto "A queda da casa de Usher", para descrever a aparência do aristocrata Roderick Usher.
} 
algo sério, não uma questão de imaginação ou de verdade (WILLIAMS, apud ASSELINEAU, 2009, p. 5). Desta forma, devemos não só enfatizar a importância de Poe para a formação da literatura de seu país como também reconhecer a relevância de suas contribuições para gerações subsequentes de escritores. Exemplos não nos faltam: Mário de Andrade, Julio Cortázar e até Machado de Assis retomaram, rediscutiram e reelaboraram a teoria da unidade de efeito. Este é também um dos objetivos deste trabalho: compreender e refletir, ainda que brevemente, como estes autores se posicionaram em relação às teorias de Poe, contribuindo assim para a consolidação do conto enquanto gênero de ficção.

\section{Edgar Allan Poe e o Romantismo norte-americano}

A fim de entender as condições que favoreceram o surgimento do conto, é necessário discorrer a respeito do contexto norte-americano de princípios do século XIX. Após a revolução de 1776, teve início um grande processo de expansão territorial que diminuiu os contatos com a Europa e fortaleceu o nacionalismo norte-americano. Desde a revolução até 1820, a área do país dobrou mais da metade; a população americana saltou de 9 milhões em 1820 para 23 milhões em 1850. A “nova literatura” começa a ser produzida por volta de 1820 , tendo como principais características o nacionalismo e a busca de uma independência em relação à literatura britânica. Com a expansão das primeiras instituições de ensino superior, o contingente de leitores começou a crescer. Este crescimento também se verificou graças ao avanço das técnicas de impressão e publicação, à melhora dos meios de comunicação e à sofisticação da vida urbana. Nova York e Boston se tornaram os mais importantes centros literários dos EUA, produzindo grandes oradores, professores e escritores, entre eles o transcendentalista Ralph Waldo Emerson. O Romantismo norte-americano foi baseado na imitação de poetas ingleses como Wordsworth e Coleridge, mas com fortes contornos nacionalistas, uma vez que o surgimento da estética romântica coincidiu com o despertar da consciência nacional americana. Os primeiros escritores que se preocuparam com a construção de uma literatura nacional foram Washington Irving, William Cullen Bryant e James Fenimore Cooper. Bryant é considerado o emancipador da poesia dos EUA, pois conferiu-lhe espontaneidade e simplicidade. Washington Irving, por sua vez, iniciou a carreira como humorista, tornando-se mais tarde um autor romântico. Ele manifesta um gosto pelo sentimentalismo, pelo passado lendário e pela bondade da natureza humana, tendo sido influenciado pelos romances de Sir Walter Scott. Fenimore Cooper explorou o nacionalismo, 
situando suas narrativas nas áreas da fronteira norte-americana, desenvolvendo o chamado romance de fronteira, que se popularizou na famosa obra $O$ último dos moicanos.

Poe, que nasceu em Boston mas produziu sua obra no sul dos EUA, foi influenciado principalmente por Samuel Taylor Coleridge, influência esta que fica bastante clara em Poems, publicado em 1831. Os poemas de Coleridge são retratados em lugares distantes e misteriosos, se referindo muitas vezes a um passado medieval, que é uma das preferências dos poetas românticos. Ele se interessava por magia, ocultismo, misticismo e hipnotismo, explorando os desvios da mente humana e as atmosferas pesadelares que eram características do consumidor de ópio, já que o próprio Coleridge consumia esta droga. Assim como o poeta inglês, Poe acreditava que o objetivo da poesia era falar de beleza, e com isso acaba "rompendo com todas as tendências moralistas e filosóficas da América do Norte, escarnecendo as especulações poéticas dos transcendentalistas" (TAYLOR, 1956, p. 118). Desta maneira, o autor se coloca contra a perspectiva que concebia a literatura como algo moralizante, que deveria inculcar valores éticos e até mesmo religiosos nos leitores. Para ele, o objetivo da literatura era, além de falar de beleza, criar uma sensação de prazer, de deleite, permitindo ao leitor uma fuga da realidade e a imersão em um mundo sobrenatural e imaginário. Com isto, Poe faz jus à ideia de suspensão da descrença defendida por Coleridge, segundo a qual o leitor, para entrar no mundo ficcional, deve dispor-se a aceitar como verdadeiras as premissas deste mundo, mesmo que elas sejam fantásticas, impossíveis e contraditórias.

A partir destas idéias, não é difícil imaginar a posição excêntrica que Poe ocupava em relação ao fazer literário de sua época. Neste sentido, o surgimento da ficção curta é de suma importância, pois, ao mesmo tempo em que sinalizava a originalidade do autor, confirmava uma tendência que estava se esboçando no mercado editorial norte-americano. $\mathrm{Na}$ década de 1850, as revistas norte-americanas publicavam um número enorme de contos, de quatro a cinco por edição. Eles se popularizaram devido ao grande público leitor, constituído principalmente por mulheres. Mas como ainda era forte a presença do romance, a ficção curta não apresentava um estatuto literário consolidado, firmando-se como um campo de experimentação artística no mundo anglo-americano. Ela foi usada não só para explorar temas fantásticos como também para introduzir novas regiões, temas e personagens, expressando novas visões de mundo e/ou a própria desordem social. Na visão de O'Connor (2004, p. 39), os norte-americanos são grandes contistas: "eles desenvolveram tão bem o conto curto que 
esta forma parece ser americana"4. De acordo com Pratt (1994, p. 104), o conto foi considerado por muitos uma forma de sinalizar o suposto fim da dominação literária britânica na literatura dos EUA. Pela primeira vez os escritores da América do Norte tinham encontrado uma forma própria de fazer literatura que traduzia os anseios de uma nação independente, seja representando a natureza como fez Irving, seja retratando o sobrenatural como fez Poe, seja expressando e/ou contestando a ideologia puritana como fez Hawthorne.

Além disso, o conto era visto como uma forma de se expressar o mundo dos sonhos e do inconsciente. Isto talvez possa explicar a abundância de narrativas curtas de mistério e terror, que tematizam os excessos e os desvios da mente humana. Sem dúvida o conto foi o principal veículo de expressão da literatura fantástica e sobrenatural, tópicos marginalizados por uma tradição romanesca calcada no realismo. É óbvio que há uma série de romances representando o sobrenatural, tais como os de Ann Radcliffe, mas tal representação não é a mesma que observamos no conto. Um dos objetivos da ficção curta é isolar um determinado momento da vida humana e representar o ser humano solitário, e desta forma os estados emocionais dos personagens podem ser retratados de forma minuciosa. A maioria deles é complexa e passa por mudanças internas, conforme percebemos no conto "Berenice", de Poe, narrado em primeira pessoa por Egeu, um intelectual que vive compenetrado na leitura de seus livros e em suas meditações na biblioteca. Quando sua prima Berenice adoece, ele começa a ficar agitado e a ter uma série de fantasias com a jovem a ponto de lhe propor casamento, algo que não havia passado pela sua cabeça enquanto ela estava saudável. A excentricidade e o desequilíbrio emocional de figuras como esta parecem explicar a associação de formas ficcionais curtas com o mergulho no universo psicológico dos personagens e a sondagem de mundos oníricos que escapam à compreensão humana. Isto fica bastante claro em outros contos de Poe, tais como "O coração denunciador", "O gato preto", "O barril de Amontillado" e "A máscara da morte rubra". Neste sentido, é possível identificar a tendência a representar, no conto, personagens tidos como outsiders, uma vez que o gênero curto permite a exploração de figuras que transgridem as regras sociais (O'CONNOR, 2004, p. 18).

\section{Review of Twice-Told Tales e o surgimento do conto enquanto gênero ficcional}

\footnotetext{
4 "Americans have handled the short story story so wonderfully that one can say it is a national form". (minha tradução)
} 
Tendo atuado como crítico e editor, Poe foi o primeiro a refletir a respeito da ficção curta, por meio das resenhas sobre Twice Told-Tales. Ao analisar tais textos, iremos nos deter em aspectos fundamentais para a compreensão da teoria da unidade de efeito e dos problemas teóricos suscitados por ela.

Um aspecto que não pode deixar de ser problematizado diz respeito à diferença entre os termos tale e short story. Tale se refere a uma narrativa relatada oralmente, na qual, segundo MAY (2004) não há um aprofundamento na psique dos personagens, que são apenas alegorias criadas com o objetivo de provar uma determinada moral. O termo short story, por sua vez, se refere a um gênero de ficção no qual há uma unidade de efeito, além de personagens complexos, que passam por mudanças internas. No presente trabalho, optei por usar o termo conto ou ficção curta como equivalente de short story na língua portuguesa, a fim de uniformizar a terminologia utilizada. Em suas resenhas, Poe usa o termo tale para se referir a conto, o que nos indica que o termo short story ainda não era usado naquela época, tendo sido adotado posteriormente.

Em suas duas primeiras resenhas, Poe faz grandes elogios aos contos de Hawthorne, atitude esta que não observamos na terceira resenha, na qual ele afirma que o escritor não é de forma alguma original, e sim singular. A falta de originalidade de Hawthorne vem do fato de que seus contos são tales, isto é, meras alegorias morais que, na visão de Poe, obliteram os sentidos das narrativas, uma vez que "se, alguma vez, uma alegoria obteve algum resultado, foi à custa da aniquilação da ficção" (POE, 2004, p. 9). Com esta afirmação, o autor sugere que os contos de Hawthorne não são short stories, pois carecem da originalidade que deve acompanhar este gênero ao lançar mão de narrativas alegóricas que possuem um fundo moral. As críticas a Hawthorne parecem ter relação com a cisma nutrida por Poe em relação ao establishment literário de sua época, aspecto este que se faz presente de forma muito clara nas resenhas. Neste sentido, não podemos deixar de sublinhar que Hawthorne era um escritor da Nova Inglaterra, cuja produção literária se caracteriza pelo puritanismo e pela preocupação excessiva com a moral cristã e o pecado original. Além disso, Hawthorne era filiado ao movimento transcendentalista, sendo amigo de Ralph Waldo Emerson. A literatura de Poe, por outro lado, não comungava com os princípios e valores do Transcendentalismo, uma vez que ele escrevia contos de terror, mistério e morte. Sendo assim, podemos interpretar as censuras de Poe como manifestações de uma certa repulsa em relação às "panelinhas insolentes que acossam nossa literatura" (POE, 2004, p. 4). É importante também ressaltar que, ao longo das resenhas, se faz presente a crença de que a literatura norte-americana carece 
de obras de real mérito e valor, e, ao afirmar isso, Poe não só critica seus contemporâneos como também clama por originalidade e por um fazer literário que fosse, de fato, norteamericano.

No primeiro parágrafo da primeira resenha, que foi publicada na Graham's Magazine em abril de 1842, Poe lança os principais motes da reflexão sobre o conto, suscitando alguns problemas teóricos que devem ser problematizados. Além de reconhecer as possibilidades da ficção curta como forma de expressão artística, o autor afirma que ela "possui vantagens peculiares sobre o romance, é uma área muito mais refinada que o ensaio, e chega a ter pontos de superioridade sobre a poesia" (POE, 2004, p. 1). A comparação do conto com o romance é, de fato, frequente nos manuais de crítica literária. Em relação ao romance, o conto apresenta um referencial teórico mais restrito por ser, obviamente, um gênero mais recente. Para Pratt (1994, p. 95), o conto é uma construção artística na qual se dá a comunicação de uma sequência limitada de acontecimentos, experiências ou situações de acordo com uma ordem que possui uma totalidade própria. E na visão de Fergusson (1994, p. 218), "o conto é definido em termos de unidade de efeito, técnicas de compressão do enredo, revelação ou mudança de personalidade, sem falar no lirismo". Tal forma de ficção apresenta apenas fragmentos da vida, "pedaços" da existência humana, de forma que as digressões são omitidas, pois a ideia é oferecer ao leitor subsídios suficientes para interpretar a narrativa, sem grandes reflexões a respeito de um tema e/ou de um personagem. De acordo com O'Connor (2004, p. 13), o objetivo do conto seria satisfazer o leitor individual, crítico e solitário, pois tal leitor, inserido em um contexto marcado pela rapidez na comunicação e pela agilidade da vida moderna, não teria tempo hábil para ler um romance, preferindo a leitura de uma narrativa curta.

Mary Louise Pratt sustentava a opinião de que a ficção curta era incompleta em relação ao romance, uma vez que este último representava a vida humana em sua totalidade, enquanto o conto iluminava apenas uma parte de uma teia maior de acontecimentos. (PRATT, 2004, p. 99). Entretanto, Poe, em sua segunda resenha, publicada em maio de 1842, continua a afirmar que o conto é superior ao romance, uma vez que não é possível ler este último "de uma só assentada" (POE, 2004, p. 3). Na visão do autor, durante a leitura do conto o leitor deve ficar à mercê do escritor, o que preconiza um domínio da técnica literária que se manifestará também na composição da narrativa. A esse respeito, Poe afirma que

Um artista literário habilidoso constrói um conto. Se é sábio, não amolda os pensamentos para acomodar os incidentes, mas, depois de conceber com cuidado deliberado a elaboração de um certo efeito único e singular, cria os incidentes 
combinando os eventos de modo que possam melhor ajudá-lo a estabelecer o efeito anteriormente concebido. Se a primeira frase não se direcionou para esse efeito, ele fracassa já no primeiro passo. Em toda a composição não deve haver sequer uma palavra escrita cuja tendência, direta ou indireta, não leve àquele único plano préestabelecido. Com tal cuidado e habilidade, através desses meios, um quadro por fim será pintado e deixará na mente de quem o contemplar um senso de plena satisfação. A ideia do conto apresentou-se imaculada, visto que não foi perturbada por nada. Este é um fim a que o romance não pode atingir. A brevidade excessiva é censurável tanto no conto quanto no poema, mas a excessiva extensão deve ser ainda mais evitada. (POE, 2004, p. 3)

Tais ideias parecem revelar uma excessiva racionalização do fazer literário, expressa em noções categóricas e programáticas a respeito da criação ficcional, mas na realidade apontam para a existência de um artista extremamente consciente das técnicas que devem ser utilizadas para a elaboração bem sucedida de uma narrativa curta. A subordinação dos incidentes narrados a um efeito único e singular remete a um princípio de coerência que deve existir no texto de ficção, a fim de criar no leitor uma impressão derivada da totalidade. Desta maneira, Poe reafirma a superioridade do conto sobre o romance, argumentando que este jamais poderia atingir a unidade de efeito de uma narrativa de curta extensão.

Poe prossegue sua argumentação afirmando que a Beleza é o objetivo do poema, conforme explicitado em "A filosofia da composição", ao passo que o objetivo do conto seria a Verdade. $\mathrm{O}$ autor volta a dizer que há poucos contos americanos de real valor, com exceção dos Tales of a Traveller, de Washington Irving, e os Twice Told-Tales. Neste sentido, Poe sustenta que "de vez em quando, encontram-se em nossos periódicos artigos que podem ser vantajosamente comparados aos melhores exemplares das revistas britânicas. Mas, geralmente, estamos muito atrás de nossos progenitores neste departamento da literatura" (POE, 2004, p. 4). Ao analisar esta citação, percebemos o quanto Poe era consciente não só da dependência da literatura norte-americana em relação à britânica, como também da suposta inferioridade da produção ficcional dos EUA em comparação com as produções inglesas da mesma época.

$\mathrm{Na}$ terceira resenha, publicada em 1847, Poe reitera a teoria da unidade de efeito, criticando Hawthorne ao invés de elogiá-lo, destacando sua preferência pela alegoria e rotulando-o de "bom místico" (POE, 2004, p. 12). O golpe final de misericórdia é dado nas quatro últimas linhas do texto, que expressam um verdadeiro desprezo não pela pessoa de Hawthorne em si mas pelo tom geral de sua obra e pelo ideário transcendentalista que o acompanha: "que o Sr. Hawthorne emende a sua pena, procure um frasco de tinta visível, abandone sua Velha Morada, rompa com o Sr. Alcott, enforque (se possível) o diretor de The Dial e jogue aos porcos todos os números que tenha de The North American Review" (POE, 
2004, p. 13). No que concerne a esta citação, algumas informações devem ser esclarecidas para que se compreenda o sentido da crítica de Poe. Ao citar o Sr. Alcott, o autor está se referindo a Bronson Alcott, pedagogo norte-americano que comungava com algumas ideias do Transcendentalismo. The Dial era o periódico do grupo transcendentalista, e The North American Review a primeira revista literária dos EUA, criada em Boston em 1815. Sendo assim, podemos inferir que a teoria estética proposta por Poe, bem como as censuras dirigidas a Hawthorne, representam um incisivo questionamento em relação às práticas literárias e editoriais de princípios do século XIX. Isto parece nos mostrar que Poe não era simplesmente um crítico ressentido pela quase total ausência de originalidade no fazer literário de sua época, mas um verdadeiro inovador no campo da teoria literária e, principalmente, da própria literatura.

\section{Considerações finais}

De acordo com Gotlib (2006, p. 32), "a teoria de Poe sobre o conto recai no princípio de uma outra relação: entre a extensão do conto e a reação que ele consegue provocar no leitor ou o efeito que a leitura lhe causa". A problemática da extensão foi retomada por Machado de Assis na nota de prefácio de Várias Histórias, na qual o escritor brasileiro, além de fazer referência explícita a Poe, reafirma a superioridade da ficção curta sobre o romance:

\footnotetext{
Não são feitos (os contos) $)^{5}$ daquela matéria, nem daquele estilo que dão aos de Mérimée o caráter de obras primas, e colocam os de Poe entre os primeiros escritos da América. O tamanho não é o que faz mal a este gênero de histórias, é naturalmente a qualidade; mas há sempre uma qualidade nos contos, que os torna superiores aos grandes romances, se uns e outros são medíocres: é serem curtos.
}

A partir da leitura não só deste trecho mas dos contos presentes em Várias Histórias, percebemos a ressonância de Poe na produção literária do próprio Machado de Assis, que reconhece sua genialidade e as vantagens da curta extensão na elaboração ficcional. De fato, Machado recebeu considerável influência de Poe, uma vez que contos como "A cartomante", por exemplo, primam pela unidade de efeito e pelo impacto que causam no leitor. Mário de Andrade, em seu ensaio "Contos e Contistas", afirma que Machado de Assis é um dos descobridores da "forma do conto", que considera "indefinível, insondável, irredutível a receitas" (ANDRADE, 1972, p. 8). O escritor modernista inicia seu ensaio afirmando que a definição de conto é um problema de estética literária, e que cabe a cada autor definir se uma

\footnotetext{
${ }^{5}$ Grifo do autor.
} 
narrativa é conto ou não. Contudo, Mário reconhece a brevidade desta forma literária ao classificá-la como "romance para revista" (ANDRADE, 1972, p. 6), declarando que um romance jamais poderia ser publicado aos fragmentos mensais em revistas. Ao contrário de Poe, Mário de Andrade deixa em aberto a definição de conto, afirmando que ela depende de um julgamento pessoal do escritor e que um livro de contos causaria "fadiga psicológica", uma vez que o leitor deve deixar de lado os personagens de uma narrativa curta a fim de passar para a próxima. Daí a necessidade de publicação em revistas literárias, veículos mais apropriados para formas breves e concisas.

Julio Cortázar, em seu ensaio "Alguns aspectos do conto", reclama que quase ninguém se interessa pela problemática do conto, um gênero que, a seu ver, ganha cada vez mais importância na modernidade. O escritor argentino retoma a definição poeana de conto e a rediscute, criando uma metáfora que ilustra a atividade (e a criatividade) do contista:

\footnotetext{
Um bom conto é incisivo, mordente, sem trégua desde as primeiras frases. Não se entenda isto demasiado literalmente, porque o bom contista é um boxeador muito astuto, e muitos dos seus golpes iniciais podem parecer pouco eficazes quando, na realidade, estão minando já as resistências mais sólidas do adversário (CORTÁZAR, 1974, p. 152).
}

Cortázar também não perde de vista a ideia de que um conto deve apresentar intensidade e tensão, manifestas na eliminação de digressões que fujam da temática central desenvolvida pelo contista. Sem a intensidade a narrativa curta é ruim, uma vez que todos os elementos devem convergir para o tema desenvolvido. Neste sentido, é relevante sublinhar a admiração de Cortázar por Poe, visto como "o primeiro a aplicar, sistematicamente, o critério de economia, de estrutura funcional" (CORTÁZAR, 1974, p. 124). O autor também comenta que Poe escrevia seus contos com a finalidade de submeter o leitor, tanto espiritual quanto imaginativamente, e que este domínio raramente é alcançado por outros contistas. Também é importante sublinhar a comparação feita por Cortázar entre o filme e o romance, o conto e a fotografia: os primeiros se caracterizam pela extensão e pela apresentação de longos enredos, ao passo que os segundos se aproximam por flagrarem, de forma concisa, breves aspectos da vida humana. Em suma, na visão de Cortázar o conto deve ser eficaz e perdurar na memória do leitor, daí sua filiação às ideias de Poe sobre a unidade de efeito.

Com base em tudo o que foi exposto no presente artigo, foi possível observar que, ao teorizar a respeito do conto, Edgar Allan Poe foge do estereótipo normalmente associado ao escritor romântico, em uma época na qual, de acordo com Cortázar, "o Neoclassicismo convidava a espraiar ideias e engenho sob pretexto de qualquer tema, e a influência romântica 
induzia a efusões incontroladas e carentes de toda a vertebração" (CORTÁZAR, 1974, p. 124). É na incisiva crítica ao Transcendentalismo e na lúcida teorização sobre o gênero conto que se revela a faceta racional e arguta de Poe, muitas vezes obliterada pelo seu alcoolismo e principalmente por sua obscura morte, para a qual, até hoje, não foi encontrada uma razoável explicação.

\section{Referências}

ANDRADE, M. de. O empalhador de passarinho. 3 ed. Brasília: INL, 1972.

ARAÚJO, R. Edgar Allan Poe: um homem em sua sombra. São Paulo: Ateliê Editorial, 2002.

ASSELINEAU, R. Edgar Allan Poe. Minneapolis: Minnesota Archive Editions, 2009.

ASSIS, M. de. Várias Histórias. São Paulo: Jackson Editores, 1957.

CORTÁZAR, J. Valise de cronópio. Tradução de Davi Arrigucci Jr. São Paulo: Perspectiva, 1974.

FERGUSON, S. Defining the short story: Impressionism and form. In: MAY, C. (org). The new short story theories. Athens: Ohio University Press, 1994. p.218-231.

GOTLIB, N. Teoria do conto. São Paulo: Ática, 2006.

HAYES, K. J. The Cambridge companion to Edgar Allan Poe. Cambridge: Cambridge University Press, 2002.

MAY, C. (org). The new short story theories. Athens: Ohio University Press, 1994.

O'CONNOR, F. The lonely voice: a study of the short story. Hoboken: Melville House Publishing, 2004.

POE, E. A. Ficção completa, poesia e ensaios. Tradução de Oscar Mendes. Rio de Janeiro: Aguilar, 2001.

. Resenhas sobre Twice-Told Tales, de Nathaniel Hawthorne. Tradução de Charles

Kiefer. Bestiario, Porto Alegre, v.1, n.6, 2004. Disponível em: http://www.bestiario.com.br/6.html Acesso em: 31 out. 2011.

PRATT, M. L. The short story: the long and the short of it. In: MAY, C. (org). The new short story theories. Athens: Ohio University Press, 1994.

SPILLER, R. The cycle of American literature. New York: McMillan Company, 1963.

TAYLOR, W. F. A história das letras americanas. Tradução de Luzia Machado da Costa. Rio de Janeiro: Fundo de cultura, 1956. 
[Recebido em agosto de 2011 e aceito para publicação em outubro de 2011]

\title{
Edgar Allan Poe and the appearance of the short-story as a genre of fiction
}

\begin{abstract}
This paper aims to describe, discuss and analyze the appearance of the short story as a genre of fiction, using Edgar Allan Poe's Review of Twice-Told Tales as a starting point for this reflection. In these critical papers, Poe analyzes Nathaniel Hawthorne's short stories, proposing the theory of the unity of effect, as well as the thesis that short narratives could be the appropriate vehicle for expressing the highest talents of an artist. The North-American literary context from the beginning of the $19^{\text {th }}$ century will also be analyzed, as it was the period in which Poe produced his works and in which the short story has consolidated itself as a genre of fiction. In this sense, some theoretical aspects regarding short narratives will be explored, in order to problematize some ideas aroused by Poe's theory. Finally, some of Poe's influences on literary criticism will be considered, as authors such as Mário de Andrade, Machado de Assis and Julio Cortázar seek to reelaborate and propose new discussions about Poe's notions about the short story.
\end{abstract}

Keywords: Short-story. Genre of fiction. Unity of effect

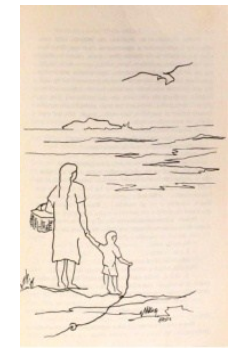

